\title{
O CUSTO DO PROCESSO: EFICIÊNCIA, INDISPONIBILIDADE DO INTERESSE PÚBLICO E ANÁLISE ECONÔMICA DO DIREITO
}

\section{THE COST OF THE PROCESS: EFFICIENCY, INDISPONIBILITY OF PUBLIC INTEREST AND ECONOMIC ANALYSIS OF LAW}

\begin{abstract}
Elon Kaleb Volpi
Mestrando do Programa de Pós-graduação de Processo e Cidadania da Universidade Paranaense - UNIPAR. Professor da Faculdade Alfa de Umuarama e Procurador da

Fazenda Nacional
\end{abstract}

\section{Jussara Suzi Assis Borges Nasser Ferreira} Doutora em Direito das Relações Sociais pela Pontifícia Universidade Católica de São Paulo - PUC. Mestra em Direito pela Universidade Estadual de Londrina - UEL. Professora permanente do Programa de Doutorado e Mestrado em Direito da Universidade de Marília - UNIMAR e do Programa de Mestrado em Direito e Cidadania da Universidade Paranaense - UNIPAR

Kelly Cardoso

Bolsista Capes PNPD junto ao Programa de Mestrado em Processo e Cidadania da Universidade Paranaense - UNIPAR. Doutora em Direito Privado pela Pontifícia Universidade Católica de Minas Gerais - PUCMinas. Mestra em Direito pela Universidade Paranaense - UNIPAR. Advogada

RESUMO: O presente artigo tem por objetivo investigar a importância da análise econômica do direito e a indisponibilidade do interesse público em relação ao custo do processo. A problematização está expressa pela não judicialização de demandas, onde o custo do processo supera a possível obtenção de resultados eficientes, como ocorre nas execuções fiscais ajuizadas, por dever, pela advocacia pública vinculada pelos princípios da legalidade e indisponibilidade do interesse público. Por meio da metodologia dedutiva, utiliza-se do estudo do IPEA, sobre o custo do processo judicial, bem como, da análise bibliográfica e legislativa.

PALAVRAS-CHAVE: Custo do processo; Princípio da eficiência; Análise econômica do direito; Indisponibilidade do Interesse Público;

ABSTRACT: This article aims to investigate the importance of the economic analysis of the law and the unavailability of the public interest in relation to the cost of the process. 
The problematization is expressed by the non-judicialization of demands, where the cost of the process exceeds the possible obtaining of efficient results, as occurs in tax executions filed, due to duty, by public advocacy linked to the principles of legality and unavailability of the public interest. Through the deductive methodology, it uses the IPEA study, on the cost of the judicial process, as well as the bibliographic and legislative analysis.

KEYWORDS: Cost of the process; Principle of efficiency; Economic analysis of law; Unavailability of Public Interest;

\section{INTRODUÇÃO}

Embora o Direito seja uma ciência com seus métodos próprios e principiologia, é evidente que sofre o influxo de outros ramos do conhecimento, sendo um desses ramos a Economia.

Cada vez mais a análise econômica do direito é utilizada como vetor, tanto para a produção, como para a aplicação de normas pelo Poder Judiciário e demais atores processuais. Isso não significa dizer que o Direito restou subserviente à Economia, mas sim, que, dada à relevância desta na tomada de decisões em geral, não se pode deixar de reconhecer sua influência. O Direito, como ciência do dever-ser, também molda a Economia, na medida em que limita, ou tenta limitar, abusos do poder econômico. Essa é inclusive, uma das preocupações do direito concorrencial e, também, do direito eleitoral.

Com efeito, o abuso do poder econômico no âmbito eleitoral, por exemplo, é bastante grave, pelas consequências nefastas ao processo democrático.

Reconhecida tal interdependência das matérias, este estudo pretende perquirir, com base no método dedutivo, como a análise econômica do direito pode influenciar a condução de processos pela advocacia pública. Para tanto, a questão deve ser analisada sob o prisma do princípio da eficiência na Administração Pública, balizador seguro, apto a orientar a atuação do Estado em Juízo, especialmente em tempos de cortes de despesas e teto de gastos. O custo do processo e consequente retorno, passam a ser fatores de reflexão e consideração para orientar o ajuizamento de execuções fiscais.

Estudo relevante do Instituto de Pesquisa Econômica Aplicada - IPEA sobre o custo do processo judicial será objeto de análise, na medida que demonstra as cifras que 
envolvem cada processo, juntamente com o custo global do Poder Judiciário e sua proporção no Produto Interno Bruto - PIB brasileiro.

Por fim, será abordada a questão do dogma da indisponibilidade do interesse público, em suas facetas primária e secundária. Afinal, se a indisponibilidade for levada a ultima ratio, permaneceria a distância em relação à eficiência, como versada pela análise econômica do direito. Por outro lado, ao se analisar o tema sob o prisma econômico, a atuação judicial da Fazenda Pública pode se tornar mais racional. Com efeito, a possível relativização da indisponibilidade do interesse público permitirá, de forma mais eficaz, atingir os fins do processo.

\title{
2 O PRINCÍPIO DA EFICIÊNCIA COMO SUPEDÂNEO DA ANÁLISE ECONÔMICA DO DIREITO
}

O princípio da eficiência, incluído no art. 37 da Constituição Federal pela Emenda Constitucional $n^{\circ}$ 19/1998, acrescentou um novo parâmetro para a atuação da administração pública ${ }^{1}$.

Embora a necessidade de se pautar a conduta da Administração Pública pela eficiência seja óbvia, com frequência aquilo que é evidente precisa ser dito, e, nesse caso, constar do texto constitucional.

Então, ao lado da legalidade, da impessoalidade, e da moralidade, há de ser atendida a eficiência ${ }^{2}$. Segundo Di Pietro, o princípio da eficiência apresenta:

\begin{abstract}
na realidade, dois aspectos: pode ser considerado em relação ao modo de atuação do agente público, do qual se espera o melhor desempenho possível de suas atribuições, do que se espera o melhor desempenho possível de suas atribuições, para lograr os melhores resultados; e em relação ao modo de organizar, estruturar, disciplinar a Administração Pública, também com o mesmo objetivo de alcançar os melhores resultados na prestação do serviço público (2007, p. 75).
\end{abstract}

\footnotetext{
${ }^{1}$ É importante registrar que o Decreto -Lei n. 200/1967 fazia menção à eficiência administrativa, quando tratava da relação entre a supervisão ministerial e a administração indireta.

${ }^{2} \mathrm{Na}$ definição de Meirelles (2016, p. 105): “o princípio da eficiência exige que a atividade administrativa seja exercida com presteza, perfeição e rendimento funcional. É o mais moderno princípio da função administrativa, que já não se contenta em ser desempenhada apenas com legalidade, exigindo resultados positivos para o serviço público e satisfatório atendimento das necessidades da comunidade e de seus membros".
} 
Para Gasparini (2006, p. 21), a administração pública deve não só executar suas atribuições com perfeição, mas também atender a critérios de rendimento. Nesse sentido, deve-se buscar maximizar os resultados para o fim de obter uma boa relação custobenefício. Essa é a palavra-chave para compreensão do princípio da eficiência.

Junto ao princípio da eficiência, costuma-se traçar a diferença entre eficácia e efetividade. Nos dizeres de Cunha (2014, p. 65-84.):

\begin{abstract}
A eficiência não se confunde com a eficácia, nem com a efetividade. Numa noção mais elementar, eficácia consiste na aptidão para produzir efeitos, enquanto a eficiência mede a relação entre os meios empregados e os resultados alcançados. (...) Por sua vez, a eficiência, como já registrado, mede a relação entre os meios empregados e os resultados alcançados. Quanto maior o rendimento de produção mais eficiente será a atividade desenvolvida. A eficiência relaciona-se com o alcance de finalidades pré-estabelecidas, dizendo respeito aos meios empregados para tanto. Haverá eficiência se os meios adotados forem ótimos, gerando pouco esforço ou dispêndio, com o resultado possível. A eficácia é, então, uma noção lógico-normativa, enquanto a efetividade constitui uma noção empírico-normativa, sendo a eficiência uma noção finalístico-normativa.
\end{abstract}

A importância do referido princípio, tem respaldo do próprio Código de Processo Civil que adotou-o expressamente em seu art. $8^{\text {o: }}$ “Ao aplicar o ordenamento jurídico, o juiz atenderá aos fins sociais e às exigências do bem comum, resguardando e promovendo a dignidade da pessoa humana e observando a proporcionalidade, a razoabilidade, a legalidade, a publicidade e a eficiência" (BRASIL, 2015).

O princípio da eficiência, portanto, ao ter como ponto central a relação custobenefício, propugna um aspecto de racionalidade para a análise e tomada de decisão pelo gestor público. Max Weber (1968, p.251) ensina que uma das condições para o desenvolvimento da atividade econômica, em uma economia capitalista, é o Direito racional, isto é, o direito calculável ${ }^{3}$.

Esse aspecto de racionalidade é destacado, também, por Timm (2012, p. 393) “um agente racional dificilmente proporia uma ação cujos custos imediatos fossem superiores ao que espera receber com o julgamento final da ação". E segue dizendo: "[...] quanto maiores forem os custos do processo, menor será a taxa de apresentação e demandas em um sistema judicial de atribuição; em sentido inverso, quanto menores as despesas, maior será a taxa de apresentação".

\footnotetext{
${ }^{3}$ Para que a exploração econômica capitalista proceda racionalmente precisa confiar em que a justiça e a administração seguirão determinadas pautas.
} 
A Análise Econômica do Direito - AED tem como objetivo constatar a economia e eficiência de determinado instituto jurídico. Para a AED essa racionalidade estaria ligada ao fato de os agentes agirem de forma minimamente racional, fazendo escolhas e "precificando" suas condutas de acordo com as normas jurídicas. É a chamada teoria da escolha racional. A partir de uma boa escolha na aplicação dos recursos, é possível potencializar os resultados, com o objetivo de ser mais eficiente.

Para Salama (2008, p.3), Posner, autor estadunidense, é um dos principais expoentes da análise econômica do direito e, logo no início de seus estudos sobre o tema, utiliza a AED como um dos vetores para a geração de maximização da riqueza social. A racionalidade do Direito serviria para promover essa maximização.

Nessa linha, segundo Timm (2012, p.14), o trabalho inicial da AED nos Estados Unidos era demonstrar a verificação empírica dos pressupostos teóricos. Buscava revelar como o common law evoluiu de tal forma a promover a eficiência das relações sociais. Com efeito, o sistema de precedentes teria se desenvolvido de forma a reduzir custos sociais nas relações. Sob esse aspecto, a AED seria eminentemente descritiva.

Então, a AED buscaria analisar se determinado instituto jurídico revela racionalidade econômica e eficiência. Para a AED essa racionalidade está ligada ao fato de os agentes se comportarem de forma minimamente racional. Isso significa que ao fazer escolhas, estarão “precificando" suas condutas de acordo com as normas jurídicas (teoria da escolha racional) (TIMM, 2018, p.14). Uma boa escolha na aplicação dos recursos, potencializaria os resultados e se revelaria, assim, mais eficiente.

Entretanto, esse argumento foi muito criticado. Uma das críticas partiu de Dworkin, para quem a ideia de eficiência não poderia ser aplicada ao Direito (um sistema normativo). Sobre o conceito de "maximização da riqueza", Dworkin (2001, p. 361) declara:

Agora porém, vem o cerne do problema. A análise econômica sustenta, em seu aspecto normativo, que a maximização da riqueza social é um objetivo digno, de modo que as decisões judiciais deveriam tentar maximizar a riqueza social atribuindo, por exemplo, direitos aos que os comprariam, não fossem os custos da transação. Mas não está claro por que a riqueza social é um objetivo digno. Quem pensaria que uma sociedade que tem mais riqueza, tal como é definida, é melhor ou está em melhor situação que uma sociedade que tem menos, a não ser alguém que cometeu o erro de personificar a sociedade e, portanto, pensou que uma sociedade está em melhor situação se tem mais riqueza, da mesma maneira que ocorre com qualquer indivíduo? Por que alguém que não cometeu esse erro deveria pensar que a maximização da riqueza social é um objetivo digno? 
Em face de tais críticas, houve uma revisão de posicionamento de Posner, o qual passou a atribuir uma menor intensidade à maximização de riqueza e a defender o pragmatismo jurídico. Ora, Posner deu, assim, um novo quadro à noção de que a eficiência possa ser útil ao Direito. Ele teria passado a considerar a eficiência não mais como o critério principal e suficiente para avaliar as questões relativas à análise econômica do Direito (SALAMA, 2008).

Segundo a análise de Salama (2008, p.13), Posner teria reconhecido que situações extremas como exploração de menores, tortura, trabalho escravo, discriminações de diversos tipos necessitam ser tratadas sem que o critério da eficiência seja o principal valor "fundacional". Para Posner (1995, p.23), “em algum momento mesmo o indivíduo fortemente comprometido com a análise econômica do direito terá que tomar uma posição em questões de filosofia política e de filosofia moral"4 (tradução nossa).

Por essa linha (pragmática), o juiz precisar ponderar as consequências de sua decisão, sem deixar de observar os valores democráticos, a Constituição e a separação dos poderes.

Assim, a eficiência não pode se equiparar à justiça, mas o processo decisório pode ganhar se levar em conta a questão da eficiência. Nesse sentido, a aplicação da justiça que desconsidere as consequências práticas seria incompleta (SALAMA, 2008, p.13).

É importante que a atuação dos atores jurídicos leve em conta essas novas formas de pensar e olhar a questão posta em juízo.

Em síntese, por mais que devam ser consideradas as críticas de Dworkin a Posner e à AED, não se pode menosprezar a noção de racionalidade, eficiência e de segurança jurídica que devem nortear a atuação judicial da fazenda pública.

Ainda, para Timm (2012, p. 398): "quando mais informadas as partes a respeito dos dados constitutivos dos elementos que referenciam a construção das expectativas recíprocas, maior é a tendência que as conciliações alcancem um patamar que reflita efetivamente a compensação devida dos danos sofridos”. Assim sendo, é importante

\footnotetext{
4 "At some point even one strongly committed to the economic approach to law will have to take a stand on issues of political and moral philosophy."
} 
lembrar que essa racionalidade é sempre mais rapidamente obtida com o acesso a informações e conhecimento por parte dos envolvidos.

Custo e eficiência expressam condições para releitura indispensáveis à consecução dos fins do processo.

\section{O CUSTO EFETIVO DO PROCESSO: ESTUDOS DO IPEA}

Visto que a eficiência deva ser buscada, juntamente com outros valores, é necessário refletir sobre o modo da atuação estatal. Para isso, convém trazer elementos que indiquem os custos do processo, a fim de orientar a atuação da fazenda pública em juízo.

Nessa linha, o Instituto de Pesquisa Econômica Aplicada realizou um estudo em 2011 acerca do custo de um processo de execução fiscal na justiça federal de primeiro grau:

\footnotetext{
Tendo em vista os dados sobre o orçamento da Justiça Federal de Primeiro Grau, tem-se que seu custo diário é de $\mathrm{R} \$ 13,5$ milhões e o custo médio do processo no ano de 2009 foi de $\mathrm{R} \$ 1,58 /$ dia. Logo, o custo médio total provável do Processo de Execução Fiscal Médio (PEFM) é de R \$ 4.685,39. Quando excluídos os custos com o processamento de embargos e recursos, esse valor é de $\mathrm{R} \$ 4.368,00$. Este último valor é o indicador mais adequado à determinação do custo efetivo do processamento da execução fiscal, na Justiça Federal de Primeiro Grau.
}

Como se vê, ainda que o referido estudo já tenha alguns anos, é possível aceitar que esses números certamente não diminuíram. E revelam, do ponto de vista da relação custo/benefício (centro da eficiência) um dado objetivo a ser considerado. Não é razoável, e nem eficiente prosseguir com recursos ou mesmo ações, cujos valores buscados são menores que isso (exceção feita aos conselhos de fiscalização federal, que, em regra, cobram valores menores e dificilmente poderiam atender a tal patamar).

Observa-se, também, que o estudo levou em conta apenas as despesas do Judiciário, mas não os custos dos exequentes (Fazenda Nacional, Conselhos, etc), o que a rigor, torna aquele valor ainda maior.

Posteriormente, o IPEA fez um estudo voltado mais aos executivos fiscais ajuizados pela Procuradoria-Geral da Fazenda Nacional, tendo apresentado o seguinte valor: 
Considerando-se o custo total da ação de execução fiscal e a probabilidade de obter-se êxito na recuperação do crédito, pode-se afirmar que o breaking even point, o ponto a partir do qual é economicamente justificável promover-se judicialmente o executivo fiscal, é de R \$21.731,45. Ou seja, nas ações de execução fiscal de valor inferior a este, é improvável que a União consiga recuperar um valor igual ou superior ao custo do processamento judicial.

Com base nesse estudo, a União alterou o patamar de ajuizamento das execuções para R\$20.000,00 (Portaria MF 75/2012).

Atualmente, conforme Portaria no 33/2018, a PGFN avançou nesse critério ao criar a técnica do ajuizamento seletivo (ou condicionado) a fim de que o Poder Judiciário só seja acionado quando efetivamente existirem bens aptos à garantia da execução:

DO AJUIZAMENTO SELETIVO (OU CONDICIONADO) DE EXECUÇÕES FISCAIS Art. 33. O ajuizamento de execuções fiscais para cobrança de débitos inscritos em dívida ativa da União fica condicionado à localização de indícios de bens, direitos ou atividade econômica do devedor ou corresponsável, desde que úteis à satisfação integral ou parcial do débito a ser executado

Ao lado do custo do processo, existe um estudo comparativo sobre o custo total do Poder Judiciário brasileiro, feito por Da Ros (2015), evidenciando que o sistema judicial do Brasil consome cerca de 1,3\% do PIB:

Gráfico 1. Despesa do Poder Judiciário como (\%) percentual do Produto Interno Bruto, países selecionados

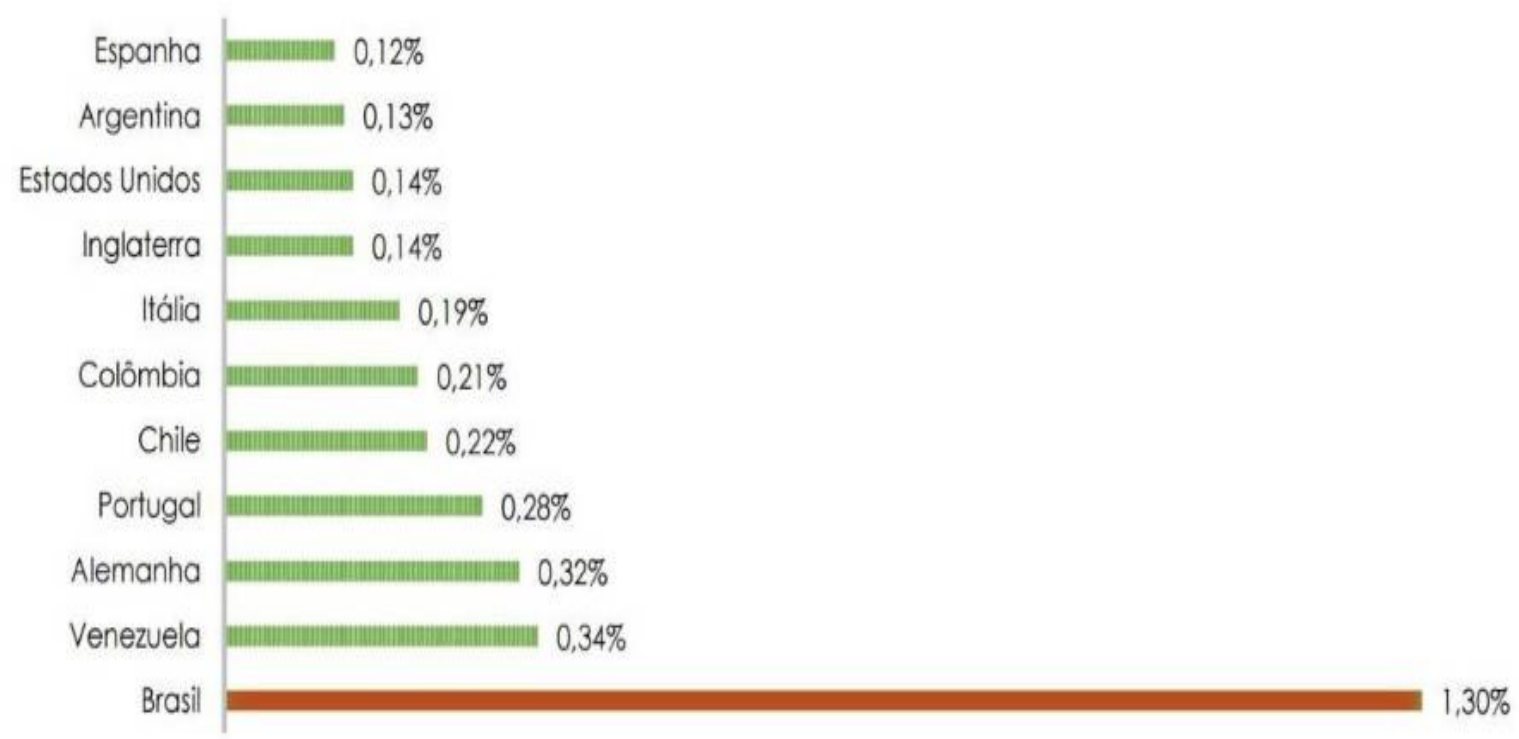

Fontes: CNJ 2014; European Commission for the Efficiency of Justice (CEPEJ) 2014, 32; Centro de Estudios de Justicia de las Américas (CEJA) 2007; National Center for State Courts (NCSC) 2012; Supreme Court of the United States (SCOTUS) 2012. 
A existência de tais estudos, sob a orientação da análise econômica do direito, permite uma atuação segura do gestor e do advogado público e uma racionalização no ingresso de novas ações no Judiciário.

Com efeito, a partir de uma visão do funcionamento do sistema, que deve considerar tanto o custo do processo como o gasto com os Poderes, é necessário, uma atuação de forma a evitar processos desnecessários, de um lado e, de outro, contribuir, quem sabe, para que os recursos orçamentários sejam mais bem alocados. Isso permitiria uma melhor performance do Poder Judiciário e dos demais atores envolvidos. Por exemplo, se um tribunal superior soluciona uma questão, em sede de recurso repetitivo, em favor do administrado, uma atuação racional da administração seria concordar com o pedido administrativo, evitando com isso, o litígio.

Recentemente, a lei da Liberdade Econômica (Lei n ${ }^{\circ}$ 13.874/2019) procurou tornar isso expresso, incluindo em seu texto a possiblidade de vinculação administrativa, desde que o tema tenha sido decidido pelo STF e STJ e haja manifestação da PGFN (art.13). Com isso será possível resolver na esfera administrativa, litígios que antes chegariam facilmente ao Judiciário. A esse respeito, Campos e Diniz (2020, p. 508) assinalam que:

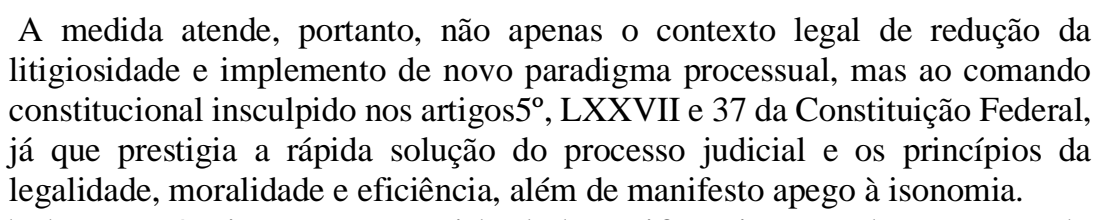

A Lei da Liberdade Econômica retoma o ideal de uniformização da atuação da fazenda pública nas esferas judicial e extrajudicial:

[...] Pode-se dizer que esta previsão está de acordo com a situação descrita pela exposição de motivos, pois parte da premissa de que o direito é único e que a ratio decidendi em uma decisão vinculante em benefício do contribuinte torna inviável a manifestação do Judiciário favorável a fisco federal para outras questões similares. (NISHIOKA; LOMBA, 220, p.524)

Como se vê, a necessidade de uma visão sistêmica da administração da justiça combinada com o princípio da eficiência impele a Fazenda Pública a uma atuação judicial e extrajudicial mais racional e uniforme.

\section{A SUPERAÇÃO DO DOGMA DA INDISPONIBILIDADE DO INTERESSE PÚBLICO}


A indisponibilidade do interesse público está relacionada ao fato de serem os gestores públicos meros curadores daquele, e não diretamente titulares.

Tais sujeitos, a rigor, não titularizam esses interesses, são apenas seus curadores, na medida em que o efetivo titular é o Estado que, em certa esfera, os protege e exercita por meio da função administrativa, "mediante o conjunto de órgãos (chamados administração, em sentido objetivo ou orgânico), veículos da vontade estatal consagrada em lei” (MELLO, 2002, p. 45). Essa distinção acerca do verdadeiro titular do interesse público é fundamental. Nesse sentido, a indisponibilidade dos interesse públicos, significa que:

sendo interesses qualificados como próprios da coletividade - internos ao setor público -, não se encontram à livre disposição de quem quer que seja, por inapropriáveis. O próprio órgão administrativo que os representa não tem disponibilidade sobre eles, no sentido de que lhe incumbe apenas curá-los que é também um dever - na estrita conformidade do que predispuser a intentio legis (MELLO, 2002, p. 73).

É curioso observar que se costuma ver o Estado como um ente abstrato que paira acima da sociedade, com o qual temos uma relação de alteralidade, isto é, ele é visto como um "outro" sujeito, mas a Teoria Geral do Estado, define que a razão de ser do Estado Moderno é o homem - ao menos no Ocidente. O Estado é concebido não mais em razão da divindade, mas em função da coletividade.

Nessa linha se manifesta Gazda (2006) em artigo sobre o poder-dever de transigir a que Administração Pública está adstrita:

\footnotetext{
É por isso e para isso que o Estado existe, constituindo-se a pessoa humana, de forma individual e coletiva, em seu princípio, seu meio e seu fim. Princípio porque quem lhe constitui são seus próprios integrantes. Meio porque é a pessoa humana integrante do Estado que deve lhe dirigir e conduzir, tanto pela participação direta como agente do Estado, como especialmente pela participação política. Fim em razão de o Estado estar constituído para assegurar aos seus membros a sobrevivência, convivência, socialização e pleno desenvolvimento.
}

Outra distinção: interesse público primário e interesse público secundário. Aquele se relaciona com os fins do Estado. Está ligado com a vontade popular expressa no texto constitucional. Este diz respeito aos interesses transitórios do Governo, que podem não coincidir com aquele. 
Para atender ao interesse público primário, pode ocorrer que o gestor deva se afastar do interesse público transitório. Imagine-se um recurso judicial cuja probabilidade de êxito é extremamente baixa, mas sob a alegação de indisponibilidade do interesse público, ele é ainda utilizado. Ora, isso pode significar ganhar um tempo mas, certamente, é uma conduta desarrazoada e ineficiente.

Essa relativização do interesse público pode ser vista em algumas leis, que autorizaram uma conduta diferenciada dos advogados públicos. A Lei nº 9.469/97, disciplinadora da atuação da Administração Federal em juízo, dentre outras coisas, expressa a possibilidade de o Estado transigir em determinados casos ${ }^{5}$.

Ao lado da referida lei, a Lei $\mathrm{n}^{\circ}$. 10.522/02 autorizou a desistência ou não ajuizamento em causas de competência da Procuradoria da Fazenda Nacional ${ }^{6}$.

\footnotetext{
${ }^{5}$ Art. $1^{\circ} \mathrm{O}$ Advogado-Geral da União, diretamente ou mediante delegação, e os dirigentes máximos das empresas públicas federais, em conjunto com o dirigente estatutário da área afeta ao assunto, poderão autorizar a realização de acordos ou transações para prevenir ou terminar litígios, inclusive os judiciais. $\S 1^{\circ}$ Poderão ser criadas câmaras especializadas, compostas por servidores públicos ou empregados públicos efetivos, com o objetivo de analisar e formular propostas de acordos ou transações. [...] $\S 3^{\circ}$ Regulamento disporá sobre a forma de composição das câmaras de que trata o $\S 1^{\circ}$, que deverão ter como integrante pelo menos um membro efetivo da Advocacia-Geral da União ou, no caso das empresas públicas, um assistente jurídico ou ocupante de função equivalente.

$\S 4^{\circ}$ Quando o litígio envolver valores superiores aos fixados em regulamento, o acordo ou a transação, sob pena de nulidade, dependerá de prévia e expressa autorização do Advogado-Geral da União e do Ministro de Estado a cuja área de competência estiver afeto o assunto, ou ainda do Presidente da Câmara dos Deputados, do Senado Federal, do Tribunal de Contas da União, de Tribunal ou Conselho, ou do Procurador-Geral da República, no caso de interesse dos órgãos dos Poderes Legislativo e Judiciário ou do Ministério Público da União, excluídas as empresas públicas federais não dependentes, que necessitarão apenas de prévia e expressa autorização dos dirigentes de que trata o caput.

$\S 5^{\circ} \mathrm{Na}$ transação ou acordo celebrado diretamente pela parte ou por intermédio de procurador para extinguir ou encerrar processo judicial, inclusive os casos de extensão administrativa de pagamentos postulados em juízo, as partes poderão definir a responsabilidade de cada uma pelo pagamento dos honorários dos respectivos advogados.

${ }^{6}$ Art. 19. Fica a Procuradoria-Geral da Fazenda Nacional dispensada de contestar, de oferecer contrarrazões e de interpor recursos, e fica autorizada a desistir de recursos já interpostos, desde que inexista outro fundamento relevante, na hipótese em que a ação ou a decisão judicial ou administrativa versar sobre:

I - matérias de que trata o art. 18;

II - tema que seja objeto de parecer, vigente e aprovado, pelo Procurador-Geral da Fazenda Nacional, que conclua no mesmo sentido do pleito do particular;

III - (VETADO).

IV - tema sobre o qual exista súmula ou parecer do Advogado-Geral da União que conclua no mesmo sentido do pleito do particular;

V - tema fundado em dispositivo legal que tenha sido declarado inconstitucional pelo Supremo Tribunal Federal em sede de controle difuso e tenha tido sua execução suspensa por resolução do Senado Federal, ou tema sobre o qual exista enunciado de súmula vinculante ou que tenha sido definido pelo Supremo Tribunal Federal em sentido desfavorável à Fazenda Nacional em sede de controle concentrado de constitucionalidade;

VI - tema decidido pelo Supremo Tribunal Federal, em matéria constitucional, ou pelo Superior Tribunal de Justiça, pelo Tribunal Superior do Trabalho, pelo Tribunal Superior Eleitoral ou pela Turma Nacional de Uniformização de Jurisprudência, no âmbito de suas competências, quando

a) for definido em sede de repercussão geral ou recurso repetitivo; ou
} 
Como se vê, cada vez mais, o legislador caminha no sentido de relativizar a indisponibilidade do interesse público em determinados casos. Com isso, a atuação da administração pública caminha de forma mais plena para além de atender o princípio da legalidade, observar o princípio da eficiência e garantir uma atuação mais equânime e voltada pra o interesse público.

Nesse sentido, cita-se como exemplo, a recente aprovação da Lei nº 13.988, de 14 de abril de 2020, que passou a permitir a transação tributária, prevista no art. 171 do CTN. Ora, ainda que não se possa transigir sobre o montante principal do tributo (apenas juros e multa), a transação seria impensável num contexto dogmático da indisponibilidade do interesse público. De igual forma, a possibilidade de autocomposição pela Administração Pública, nos termos da Lei $\mathrm{n}^{\circ} 13.140 / 2015$ e também o uso da arbitragem pela administração pública corroboram essa noção de relativização da indisponibilidade do interesse público.

É oportuno mencionar o que ensina Gazda, ao defender, sob o enfoque da teoria política, que a administração pública em Juízo possui um poder-dever de transigir. Para ele, uma vez solucionada de forma pacífica uma questão pelo Poder Judiciário, a

b) não houver viabilidade de reversão da tese firmada em sentido desfavorável à Fazenda Nacional, conforme critérios definidos em ato do Procurador-Geral da Fazenda Nacional;

VII - tema que seja objeto de súmula da administração tributária federal de que trata o art. 18-A desta Lei. $\S 1^{\circ}$ Nas matérias de que trata este artigo, o Procurador da Fazenda Nacional que atuar no feito deverá, expressamente:

I - reconhecer a procedência do pedido, quando citado para apresentar resposta, inclusive em embargos à execução fiscal e exceções de pré-executividade, hipóteses em que não haverá condenação em honorários; II - manifestar o seu desinteresse em recorrer, quando intimado da decisão judicial;

$\S 2^{\circ}$ A sentença, ocorrendo a hipótese do $\S 10$, não se subordinará ao duplo grau de jurisdição obrigatório. [...]

$\S 8^{\circ} \mathrm{O}$ parecer da Procuradoria-Geral da Fazenda Nacional que examina a juridicidade de proposições normativas não se enquadra no disposto no inciso II do caput deste artigo;

$\S 9^{\circ}$ A dispensa de que tratam os incisos V e VI do caput deste artigo poderá ser estendida a tema não abrangido pelo julgado, quando a ele forem aplicáveis os fundamentos determinantes extraídos do julgamento paradigma ou da jurisprudência consolidada, desde que inexista outro fundamento relevante que justifique a impugnação em juízo.

$\S 10^{\circ} \mathrm{O}$ disposto neste artigo estende-se, no que couber, aos demais meios de impugnação às decisões judiciais.

$\S 11^{\circ} \mathrm{O}$ disposto neste artigo aplica-se a todas as causas em que as unidades da Procuradoria-Geral da Fazenda Nacional devam atuar na qualidade de representante judicial ou de autoridade coatora

$\S 12^{\circ}$ Os órgãos do Poder Judiciário e as unidades da Procuradoria-Geral da Fazenda Nacional poderão, de comum acordo, realizar mutirões para análise do enquadramento de processos ou de recursos nas hipóteses previstas neste artigo e celebrar negócios processuais com fundamento no disposto no art. 190 da Lei $\mathrm{n}^{\circ}$ 13.105, de 16 de março de 2015 (Código de Processo Civil).

$\S 13^{\circ}$ Sem prejuízo do disposto no $\S 12$ deste artigo, a Procuradoria-Geral da Fazenda Nacional regulamentará a celebração de negócios jurídicos processuais em seu âmbito de atuação, inclusive na cobrança administrativa ou judicial da dívida ativa da União. 
administração pública teria o dever de acatá-la nos demais casos, sob pena de desvirtuamento do princípio da separação dos poderes, contrariando a lógica da estrutura estatal. Se somente isso fosse observado de forma mais efetiva, muitos recursos deixariam de ser interpostos e vários litígios seriam solucionados sem sequer chegarem ao Judiciário (GAZDA, 2006).

Observe-se que a técnica de julgamento de casos repetitivos, reafirmada no Código de Processo Civil, busca efetivar isso, na medida em que as instâncias inferiores têm o dever de respeitar e aplicar os precedentes definidos pelo Superior Tribunal de Justiça e Supremo Tribunal Federal, como se lê no art.927 do CPC (BRASIL, 2015).

Nessa senda, o princípio da eficiência deve nortear a atuação da Fazenda Pública em juízo. Talvez a melhor forma de entender o referido princípio seja traduzi-lo em uma equação que contemple a legalidade e a relação custo-benefício ou, conforme Meirelles (2016, p. 105): "Dever de eficiência é o que se impõe a todo agente público de realizar suas atribuições com presteza, perfeição e rendimento funcional”.

A administração pública em Juízo pode se deparar com situações em que o melhor (isto é, o mais eficiente) é evitar o conflito, atendendo, efetivamente o interesse público, ainda que o texto expresso na lei indique o prosseguimento da demanda, por exemplo. A interpretação adequada pelos órgãos julgadores e pelas partes, quando não contraria a Constituição Federal, ao contrário, está baseada nos princípios do Estado de Direito, deve aplicar trâmites em prol da sociedade. Nesse sentido, prossegue Gazda (2006):

[...] Fica evidente que o Estado-Administração, ao insistir em recorrer de decisões judiciais que seguem precedentes já sedimentados pelas Cortes Superiores e sem qualquer elemento novo que possa implicar alteração de entendimento, não observa os princípios da economicidade e da eficiência, aumentado custos de sua própria estrutura de defesa e do Judiciário, mormente se considerada a possibilidade de propor acordos nesses casos ou estabelecer, via Legislativo, solução para todos os casos, nas hipóteses de demandas em massa. Essa última solução, aliás, é inclusive imperativo constitucional de isonomia, conforme vem sendo exposta na presente exposição, implicando observância do interesse público primário do Estado na realização dos interesses legítimos dos administrados.

Não se olvida que o princípio da legalidade é muito caro à administração pública. Veja-se, de um lado, que o fato de a matéria já ter sido pacificada no Judiciário, não implicando uma relativização de tal princípio mas, antes, está relacionado à necessária 
submissão de um dos poderes do Estado (Executivo) ao que foi decidido por outro poder, no caso, o Judiciário. Com isso, atende-se de forma mais direta o princípio da eficiência.

Todavia, tem razão o autor quando aponta para a superação da legalidade formal - muitas vezes estéril - inserindo-a num contexto mais amplo de justificação. Com efeito, o princípio da legalidade, em verdade, é uma garantia ao administrado contra os arbítrios do Estado e não pode ser usado pela Administração Pública como um escudo para que acordos não sejam celebrados (ou que recursos judiciais sejam apresentados), sob a alegação de que não há lei permitindo a transação. Essa é a posição de Freitas (2004, p. 151):

Em Estatuto Fundamental pautado pelo princípio da unicidade da jurisdição (art. $5^{\circ}, \mathrm{XXXV),} \mathrm{a} \mathrm{Administração} \mathrm{Pública} \mathrm{precisa,} \mathrm{vez} \mathrm{por} \mathrm{todas,}$ exemplarmente acatar os pronunciamentos irrecorríveis do Poder Judiciário, sob pena de perecer a credibilidade do sistema de controle, dele subtraindo o hálito vital do respeito mútuo e da independência harmônica dos Poderes (art. $2^{\circ}$, e 60, $\S 4^{\circ}$, III, da CF).

De fato, é imperioso que haja uma definição clara dos critérios legais para a atuação da Administração Pública em Juízo. Todavia, isso não justifica a atuação irrazoável dos advogados públicos, cuja aplicação do citado princípio não leva em conta uma interpretação sistemática.

Tendo em mente que o Estado tem como fim o homem, pode-se concluir que a indisponibilidade do interesse público comporta relativizações ${ }^{7}$. Isso porque pode ocorrer de a Administração Pública estar defendendo interesse secundário (v.g. para postergar o pagamento de uma indenização ou vedar a concessão de um benefício a que a parte tem direito), quando, na verdade, o interesse público primário aconselharia o imediato cumprimento da obrigação.

Com efeito, por vezes o Poder Executivo em Juízo defende teses já afastadas de forma pacífica pela Jurisprudência, mas que continuam sendo objeto de recursos que, sabidamente, serão improcedentes, fazendo movimentar de forma desnecessária a máquina judiciária a um alto custo para o próprio Estado. Não se quer dizer com isso que as decisões dos tribunais superiores (em especial o Superior Tribunal de Justiça e o Supremo Tribunal Federal) seriam “imaculadas” e inquestionáveis, mas há matérias que

\footnotetext{
7 Convém, entretanto, que essas relativizações sejam regradas, a fim de se evitar casuísmos discriminatórios.
} 
estão sobejamente pacificadas e a reiteração do recurso não irá mudar a posição da Corte já sedimentada num sentido. É da essência do sistema jurisdicional buscar a uniformização das decisões, o que, na verdade, privilegia a isonomia ao oferecer respostas uniformes para casos idênticos.

Portanto, a indisponibilidade não deve ser vista de forma absoluta, mas sim com um olhar mais amplo e republicano, sopesado com o princípio da eficiência.

Interessante notar que desde 2002 o STF acenava com essa possibilidade (relativização da indisponibilidade do interesse público) no RE 253.885 (BRASIL, 2002):

\begin{abstract}
Transação. Validade. Em regra, os bens e o interesse público são indisponíveis, porque pertencem à coletividade. É, por isso, o Administrador, mero gestor da coisa pública, não tem disponibilidade sobre os interesses confiados à sua guarda e realização. Todavia, há casos em que o princípio da indisponibilidade do interesse público deve ser atenuado, mormente quando se tem em vista que a solução adotada pela Administração é a que melhor atenderá à ultimação deste interesse. (RE 253.885, Rel. Min. Ellen Gracie, julgamento em 4-6-02, DJ de 21-6-02)
\end{abstract}

Como visto, a busca pela realização do interesse público, por vezes, é mais complexa do que aparenta ser e a indisponibilidade do interesse público, por si só, não é suficiente para dar as respostas necessárias ao administrado e à administração pública.

\title{
5 CONCLUSÃO
}

A Economia influencia o Direito, alcançando tanto a elaboração das leis, como sua aplicação pelo Judiciário.

A análise econômica do direito pode influenciar a atuação da advocacia pública, é responsável pela condução de grande parte dos processos, nas justiça federal e estadual, sendo relevante buscar elementos para sua condução em juízo, com vistas a reduzir a litigiosidade em atenção também ao custo do processo.

Nessa linha, o primeiro obstáculo a ser enfrentado é a questão da "(in)disponibilidade" do interesse público. Tal princípio, ao lado da legalidade, é invocado com frequência pela advocacia como um óbice à realização de acordos, desistência de recursos e uma análise mais refinada do ponto de vista econômico. Foi possível verificar que a indisponibilidade do interesse público tem passado por uma conformação, em vista das graves e grandes questões que têm sido enfrentadas. 
Diversas foram as medidas tomadas que revelaram uma nova visão da indisponibilidade do interesse público que continua e deve ser bem tutelado, e a análise econômica tem elementos para respaldar, de forma objetiva, tomada de decisão acerca do ajuizamento ou não de determinadas ações, observando o custo do processo e a inviabilidade de resultados

Os estudos feitos pelo IPEA deram visibilidade e quantificaram os custos do processo. Isso foi deveras importante e ajudou a orientar a adoção de políticas de redução de litigiosidade por órgãos como a Procuradoria-Geral da Fazenda Nacional, que inclusive, ampliou os efeitos de estudo, criando uma política de não ajuizamento em caso de inexistência de bens. Isso revela a importância da análise econômica nos litígios de massa.

A aplicação do princípio da eficiência, tem o condão de ser fio condutor da atuação em juízo, agregando racionalidade, razoabilidade e eficiência ao processo.

\section{REFERÊNCIAS}

BRASIL. Decreto-Lei n. 200. Dispõe sôbre a organização da Administração Federal, estabelece diretrizes para a Reforma Administrativa e dá outras providências. $25 \mathrm{fev}$. 1967. Disponível em: <http://www.planalto.gov.br/ccivil_03/DecretoLei/Del0200.htm>. Acesso em 20 out.2019.

BRASIL. Constituição da República Federativa do Brasil de 1988. Emendas Constitucionais. Brasília: Senado, 1988. Diário Oficial da União, Brasília, 5 out. 1988. Disponível em: < http://www.planalto.gov.br/ccivil_03/Constituicao/Constituicao.htm>. Acesso em: 20 set. 2019

BRASIL. Lei Federal $\mathbf{n}^{\mathbf{0}} \mathbf{9 . 4 6 9}$. Regulamenta o disposto no inciso VI do art. $4^{\circ}$ da Lei Complementar $\mathrm{n}^{\circ} 73$, de 10 de fevereiro de 1993; [...]. 10 jul. de 1997. Disponível em http://www.planalto.gov.br/ccivil_03/Leis/L9469.htm. Acesso em 20 out.2019.

Brasil. Supremo Tribunal Federal. Poder Público. Transação. Validade. Recurso

Extraordinário no. 253.885, Rel. Min. Ellen Gracie. Brasília, DF, 04 de junho de 2002. Disponível em:

<http://www.stf.jus.br/portal/jurisprudencia/listarJurisprudencia.asp?s1=\%28253885\%2 ENUME\%2E+OU+253885\%2EACMS\%2E\%29\&base=baseAcordaos\&url=http://tinyu rl.com/yyjk8hx4>. Acesso em 21 out. 2019.

BRASIL. Ministério da Fazenda. Portaria n. 75 de 22 de março de 2012. Disponível em: <http://fazenda.gov.br/acesso-a-informacao/institucional/legislacao/portariasministeriais/2012/portaria75>. Acesso em: 20 out. 2019. 
BRASIL. Lei $\mathrm{n}^{\circ} 13.105$, de 16 de março de 2015. Código de Processo Civil. Diário Oficial da União, Brasília, 17 mar. 2015. Disponível em:

<http://www.planalto.gov.br/ccivil_03/_Ato2015-2018/2015/Lei/L13105.htm>. Acesso em: 20 out. 2019.

BRASIL. PROCURADORIA GERAL DA FAZENDA NACIONAL. Portaria 33/2018. Brasília-DF. Disponível em:

<http://sijut2.receita.fazenda.gov.br/sijut2consulta/link.action?visao=anotado\&idAto=9 0028>. Acesso em: 31 ago. 2020

BRASIL. Lei no 13.874, de 20 de setembro de 2019. Institui a Declaração de Direitos de Liberdade Econômica; estabelece garantias de livre mercado [...]. Diário Oficial da União, Brasília, 21 de set. 2019. Disponível em:

<http://www.planalto.gov.br/ccivil_03/_ato2019-

2022/2019/lei/L13874.htm\#: :text=Art.,IV\%20do\%20caput\%20do\%20art>. Acesso em: 30 ago. 2020.

CAMPOS, Rogério; DINIZ, Geila Lídia Barreto Barbosa. Comentários ao art. 13. Redução de litigiosidade e isonomia tributário: os avanços promovidos pela Lei de Liberdade Econômica (art. 13) na Lei n 10.522, de 2002. In: CRUZ, André Santa; DOMINGUES, Juliana Oliveira; GABAN, Eduardo Molan (Org). Lei da Liberdade Econômica -Lei 13874/2019 Comentada Artigo por Artigo. Salvador: Editora Juspodivm, 2020, p. 505-518.

CRUZ, André Santa; DOMINGUES, Juliana Oliveira; GABAN, Eduardo Molan (org). Lei da Liberdade Econômica -Lei 13874/2019 Comentada Artigo por Artigo. Salvador: Editora Juspodivm, 2020.

CUNHA, Leonardo Carneiro. A previsão do princípio da eficiência no projeto do novo código de processo civil brasileiro. Revista de Processo. vol. 233/2014. Jul / 2014.

DA ROS, Luciano. O custo da Justiça no Brasil: uma análise comparativa exploratória. The Observatory of Social and Political Elites of Brazil. Núcleo de Pesquisa em Sociologia Política Brasileira da Universidade Federal do Paraná. V. 2, No 9, julho/2015. Acesso em 19 jul.2020. Disponível em: <http://observatory-elites.org/wpcontent/uploads/2012/06/newsletter-Observatorio-v.-2-n.-9.pdf.>. Acesso em: 30 ago. 2020 .

DI PIETRO, Maria Sylvia Zanella. Direito Administrativo. 20 ed., São Paulo: Atlas, 2007.

DWORKIN, Ronald M. Uma questão de princípio. São Paulo: Martins Fontes, 2001. p. 365.

GASPARINI, Diógenes. Direito administrativo. 11. ed. São Paulo: Saraiva, 2006, p. 21.

GAZDA, Emmerson. Administração Pública em juízo: poder-dever de transigir.

Direito Federal: revista da Associação dos Juízes Federais do Brasil, v. 23, nº .83 , 
p.131-158, jan/mar 2006. Disponível em http://www.revistadoutrina.trf4.jus.br/ Acesso em 20 out. 2019.

INSTITUTO DE PESQUISA ECONÔMICA APLICADA - IPEA. Custo e tempo do processo de execução fiscal promovido pela Procuradoria Geral da Fazenda Nacional. Brasília, novembro de 2011. Disponível em:

<http://www.ipea.gov.br/agencia/images/stories/PDFs/nota_tecnica/111230_notatecnica diest1.pdf $>$. Acesso em 26 jun.2020.

INSTITUTO DE PESQUISA ECONÔMICA APLICADA - IPEA. Custo Unitário do Processo de Execução Fiscal na Justiça Federal. Brasília, novembro de 2011.

Disponível em:

http://repositorio.ipea.gov.br/bitstream/11058/7862/1/RP_Custo_2012.pdf. Acesso em: 26 jun.2020.

MEIRELLES, Hely Lopes. Direito Administrativo Brasileiro. 42 ed. atual. até a Emenda Constitucional 90, de 15.9.2015, São Paulo: Malheiros, 2016.

MELLO, Celso Antônio Bandeira de. Curso de Direito Administrativo. $14^{\mathrm{a}}$ edição. São Paulo: Malheiros Editores, 2002. p.45

NISHIOKA, Alexandre Naoki; LOMBA, Juliana Ferretti. Comentários ao art. 13. In: CRUZ, André Santa; DOMINGUES, Juliana Oliveira; GABAN, Eduardo Molan (Org). Lei da Liberdade Econômica -Lei 13874/2019 Comentada Artigo por Artigo.

Salvador: Editora Juspodivm, 2020, p. 519-526.

POSNER, Richard A. Overcoming Law, Cambridge, Mass.: Harvard University Press, 1995.

SALAMA, Bruno Meyerhoff. O que é "Direito e Economia'? Revista Unifacsn.160. 2013. Salvador-BA. Disponível em:

<https://revistas.unifacs.br/index.php/redu/article/view/2793>. Acesso em: 31 ago.2020.

TIMM, Luciano Benetti (org). Direito e economia no Brasil. São Paulo: Atlas, 2012.

WEBER, Max. História Geral da Economia. Trad. Calógeras A. Pajuaba. São Paulo: Mestre Jou. 1968. 